\title{
BMJ Open A retrospective analysis of factors associated with selection of end-of-life care and actual place of death for patients with cancer
}

\author{
Shunsuke Kondo, ${ }^{1,2}$ Taichi Shimazu, ${ }^{3}$ Chigusa Morizane, ${ }^{2}$ Hiroko Hosoi, ${ }^{2}$ \\ Takuji Okusaka, ${ }^{2}$ Hideki Ueno ${ }^{2}$
}

To cite: Kondo S, Shimazu T, Morizane $\mathrm{C}$, et al. A retrospective analysis of factors associated with selection of end-of-life care and actual place of death for patients with cancer. BMJ Open 2014;4:e004352. doi:10.1136/bmjopen-2013004352

- Prepublication history for this paper is available online. To view these files please visit the journal online (http://dx.doi.org/10.1136/ bmjopen-2013-004352)

Received 29 October 2013 Revised 11 March 2014 Accepted 14 April 2014

CrossMark

For numbered affiliations see end of article.

Correspondence to Dr Shunsuke Kondo; shkondo@ncc.go.jp

\section{ABSTRACT}

Objectives: The factors associated with end-of-life (EOL) care that patients with cancer selected and actual place of death (POD) is less elucidated. We analysed how specific EOL care, especially anticancer therapies, selected by patients with pancreatic carcinoma affected their POD in Japan.

Setting: A retrospective cohort study using clinical records of a single institute.

Participants: This study included 433 advanced or recurrent patients with pancreatic carcinoma who had completed standard chemotherapies and were receiving hospice care in the National Cancer Center Hospital between April 2008 and April 2011.

Outcome measures: We analysed statistical association factors, demographic information, geographical differences, medical environment, EOL care selection, along with actual POD using logistic regression analysis.

Results: Of the 433 patients, 147 selected palliative care units (PCUs) as the POD; 229, hospital; and 57, home with hospice care. POD selection was associated with several factors. Notably, EOL care selection, especially the use of complementary and alternative medicine (CAM), is associated with POD selection (death in PCU; $\mathrm{OR}=0.23, \mathrm{p}=0.02$ ).

Conclusions: This study is, to the best of our knowledge, the first to unveil that EOL care selection is associated with POD in Japan. Certain factors such as gender, medical environment and EOL care selection might influence the POD. Patients who pursue aggressive anticancer therapies, such as CAM use, were possibly deprived of a chance of early reference to a PCU.

\section{INTRODUCTION}

In Japan, the Cancer Control Act was established to improve the quality of life (QOL) of all patients with cancer, and disseminating palliative care was identified as one of the most important areas to be improved. To disseminate quality palliative care, palliative care units

\section{Strengths and limitations of this study}

- This study is the first to unveil that end-of-life care selection is associated with place of death in Japan.

- Patients who pursue aggressive anticancer therapies, such as complementary and alternative medicine use, were possibly deprived of a chance of early reference to the palliative care unit.

- Limitations of this study should be considered, including its retrospective nature and the involvement of a single institution. Therefore, the findings may not be entirely representative of patients receiving cancer treatment at other Japanese cancer hospitals.

(PGUs) and palliative care team were established. Although PCU is the most common type of specialised palliative care service in Japan, ${ }^{1}$ patients with cancer can choose their place of death (POD) as either PCUs, home with hospice or non-PCU hospitals.

Dying at a preferred place is one of the most important determinants for terminally ill patients with cancer. ${ }^{2} 3$ In some previous reports, POD for patients with cancer was influenced by several factors such as illness, demographic variables, personal variables, social support and relationship with the physician. ${ }^{45}$ Moreover, patients who optimistically estimated their prognoses are more likely to undergo aggressive treatment, but controlling for known prognostic factors, their 6-month survival is no better. ${ }^{6}$

Choice of cancer therapy at the EOL is becoming increasingly complex due to more options for therapy, high expectations from therapy, less toxic treatments and better supportive care. Consequences of these choices may have an enormous impact on patients and families (caregiver) and societal healthcare costs. Although less aggressive care, 
especially palliative care, at the EOL is associated with better QOL near death, ${ }^{7} 8$ patients with cancer are receiving increasingly aggressive care at the EOL. ${ }^{9} 10$ The use of complementary and alternative medicine $(\mathrm{CAM})$ as an aggressive anticancer therapy has been increasing worldwide over the past two decades, and an estimated $40-60 \%$ of adult patients with cancer use CAM, although it does not provide definite survival benefit and its users report clinically poor QOL. ${ }^{11}$

We hypothesised that aggressive anticancer therapy, especially CAM chosen by patients with cancer, limited their options of POD selection. Hence, we conducted this study to analyse the factors that influence POD and to show the evidence of influence of EOL care selection after standard chemotherapy on patients' POD. Moreover, we also analysed the factors that influence EOL care selection in this study.

\section{METHODS}

\section{Selection criteria}

Patients receiving hospice care at the National Cancer Center Hospital (NCCH) between April 2008 and April 2011 were selected. The inclusion criteria were as follows: confirmed as having carcinoma according to the results of histological tests, had advanced or recurrent pancreatic carcinoma, were receiving systemic palliative chemotherapy at the NCCH, failed to respond to standard chemotherapy and had discussed about EOL care with their attending physician. Prior to the start of chemotherapy, all patients included in the analysis were clearly informed that the chemotherapy being administered was not curative but aimed at prolonging their survival and palliating their symptoms. Their signed informed consent for the same was obtained. From the analysis, we excluded patients who had not been receiving standard chemotherapies or who did not choose POD. This study protocol was approved by the Institutional Review Board of the NCCH, Tokyo, Japan.

\section{Data extraction and definition of terms}

The following information was collected with regard to patients: (1) demographic (age, sex, relation with the attending physician, main family caregiver and state of disease), (2) geographical differences (distance from the cancer centre), (3) medical environment (involvement of a palliative care team, a case worker, a primary care doctor and regional healthcare cooperation during chemotherapy) and (4) EOL care selection (best supportive care (BSC), non-standard chemotherapy and CAM use).

In this study, we defined PCU as the institute has been covered by National Medical Insurance since 1990 and plays a central role in providing specialised palliative care services to patients with cancer. Since the NCCH does not have beds assigned for palliative care, patients were provided with information about PCUs near their homes or according to their wish at the start of chemotherapy or completion of standard chemotherapy. Dying at home was defined as dying at home with hospice. Other hospitals except PCUs and homes with hospice were defined as non-PCU hospitals in this study.

In this study, we defined standard therapy as gemcitabine-based or S-1-based chemotherapy. Aggressive anticancer therapy was defined as non-standard chemotherapies and CAM. Non-standard chemotherapy was defined as chemotherapy with other cytotoxic agents and included participation in a clinical trial. We used the definition of CAM adopted by the National Cancer Institute: 'CAM is the term for medical products and practices that are not part of standard medical care.' NCI categorises CAM as follows: CAM (any medical system, practice or product, ie, not thought of as standard care), complementary medicine (CAM therapy used along with standard medicine), alternative medicine (CAM therapy used in place of standard treatments) and integrative medicine (an approach that combines treatments from conventional medicine and CAM for which there is some high-quality evidence of safety and effectiveness).

\section{Statistical analysis}

We conducted statistical analyses using IBM SPSS V.18.0 (SPSS, Chicago, Illinois, USA). All patient characteristics and background factors were analysed using the logistic regression analyses. Multivariate logistic regression analyses were performed after univariate analyses to reveal strong correlation factors between POD and EOL care. $p$ Values less than 0.05 in a two-sided test were considered significant.

\section{RESULTS}

\section{Patient characteristics}

A total of 433 patients received systemic chemotherapy for advanced and recurrent pancreatic carcinoma at the NCCH (figure 1). Of these, 147 (34\%) patients chose PCU, $57(13 \%)$ patients chose home with hospice and $229(53 \%)$ patients chose non-PCU hospitals as their POD. In total, $357(82 \%)$ patients chose to receive BSC and $76(18 \%)$ patients chose aggressive anticancer treatment as EOL care. In patients with aggressive anticancer therapy, $64(15 \%)$ patients used non-standard chemotherapies and 57 (13\%) patients used CAM as EOL care (table 1).

\section{Factors influencing POD}

In multivariate logistic regression analysis using strong factors that correlated with POD in univariate analyses, patients who selected PCUs as the POD were most likely to be of female gender (OR 1.85; 95\% CI 1.23 to 2.79; $\mathrm{p}=0.003$ ) and CAM users (OR $0.23 ; 95 \%$ CI 0.06 to 0.81 ; $\mathrm{p}=0.02$ ). Patients who selected dying at home were most likely to be supported by a case worker (OR 3.50; 95\% CI 1.22 to $10.03 ; \mathrm{p}=0.02$ ) and be town dwellers (OR 2.13; $95 \%$ CI 1.18 to $3.85 ; \mathrm{p}=0.01$ ). Patients who died at non-PCU hospitals were likely to be of male gender (OR 


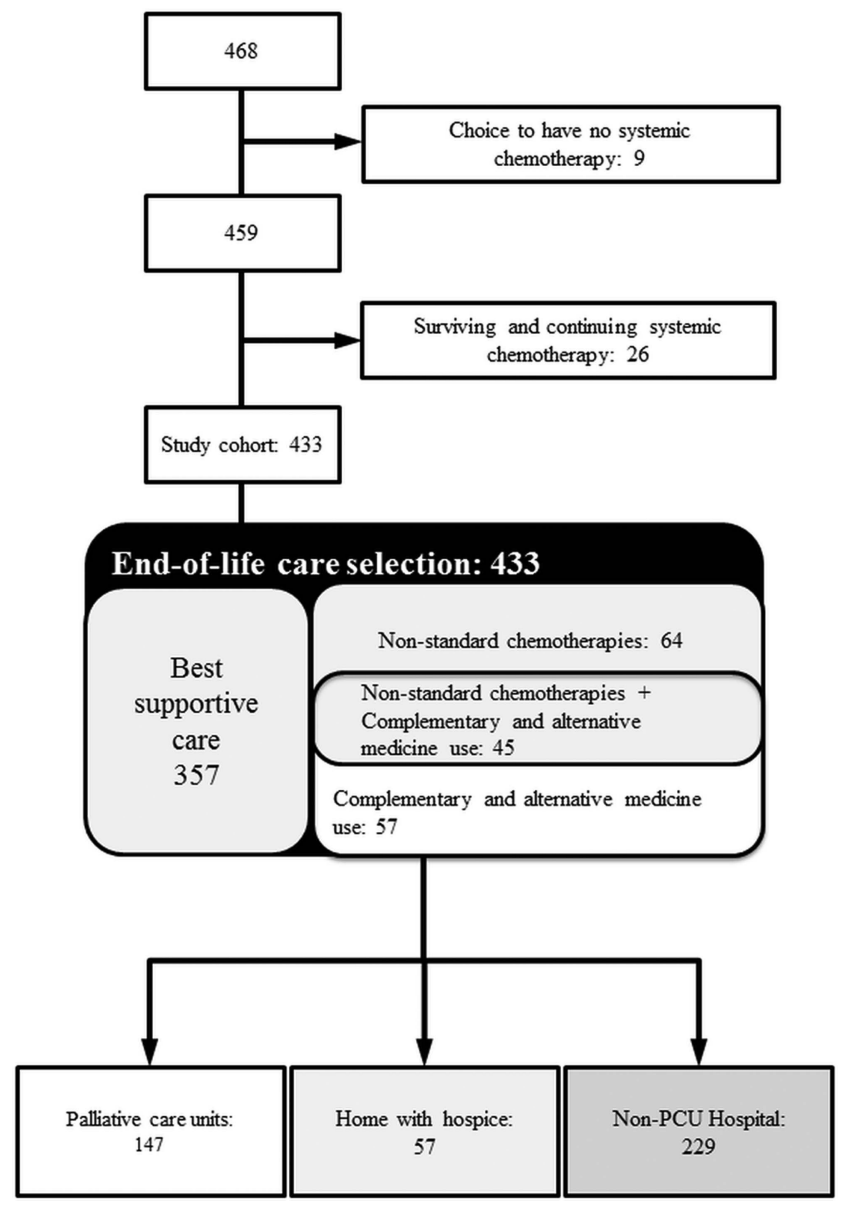

Figure 1 Patient distribution in the study. A total of 468 patients with advanced or recurrent pancreatic carcinoma were seen at the National Cancer Center Hospital. Nine patients chose best supportive care without receiving chemotherapy. Twenty-six patients are still alive and are continuing with standard chemotherapy.

1.64; $95 \%$ CI 1.10 to 2.44; $\mathrm{p}=0.02$ ), rural dwellers (OR $1.85 ; 95 \%$ CI 1.24 to $2.74 ; \mathrm{p}=0.002)$ and had involvement of a case worker (OR 2.44; 95\% CI 1.43 to 4.17; $\mathrm{p}=0.001$ ) (table 2). Although we conducted additional analyses including all variables (age, gender, caregiver, distance from the cancer centre, attending physician, state of disease, EOL selection and medical environment) into the model, the results were materially unchanged.

\section{Factors influencing EOL care selection}

Table 3 shows the results of multivariate analyses using significant factors after univariate analyses associated with EOL care selection were performed. Patients who selected BSC as EOL care were of older age $(\mathrm{OR}=1.67$; 95\% CI 1.02 to 2.78; $\mathrm{p}=0.04$ ) and had recurrence after surgical resection $(\mathrm{OR}=1.82 ; 95 \%$ CI 1.02 to 3.23 ; $\mathrm{p}=0.04)$. Patients who selected non-standard chemotherapies were of younger age $(\mathrm{OR}=2.04 ; 95 \% \mathrm{CI}$ 1.18 to $3.51 ; \mathrm{p}=0.01)$. Patients who selected CAM use were of younger age $(\mathrm{OR}=2.57 ; 95 \%$ CI 1.43 to 4.63 ; $\mathrm{p}=0.01$ ) and depended on the attending physician. Although we conducted additional analyses including all variables into the model, the results were materially unchanged.

\section{DISCUSSION}

The present study results indicate that EOL care selected by Japanese patients with pancreatic cancer after complete standard chemotherapy was correlated with the selection of POD. Notably, the factors of (1) demographic (gender), (2) geographical differences (distance from the cancer centre), (3) medical environment (involvement of a case worker) and (4) EOL care selection (CAM use) were strongly correlated with selection of POD. Moreover, patients' age, state of disease and dependence on the attending physician were strong factors that correlated with EOL care selection. We found that patients who selected aggressive anticancer therapy as EOL care, especially CAM use, tended to lose the opportunity to die in a PCU.

In Japan, a series of national surveys was conducted by the Ministry of Health, Labour and Welfare in 2008 to reveal the preferred place of care and POD. Home was the preferred place of care in general, with $29 \%$ of respondents reporting that they wanted to receive care at home and be admitted to a PCU if necessary, and $23 \%$ preferring to receive care at home and be admitted to a hospital if necessary. Another $11 \%$ chose home until death, while a considerable number of respondents reported that they want to be admitted to a hospice earlier and stay until death $(18 \%)$ or be admitted to a hospital earlier and stay until death (10\%). The distribution of POD in this study reflected the trend in the preference of Japanese patients with cancer with regard to place of care and POD.

In some previous reports, factors that influence selection of POD for patients with cancer were related to illness, ${ }^{12}$ individual factors that account for the maintenance of patients' individuality, comparison of demographic variables and personal variables, ${ }^{13}$ social support $^{4}$ and relationship with the physician. ${ }^{5}$ The present study showed gender female associated with PCU as actual POD. On the other hand, a previous British report showed gender was not associated with POD. ${ }^{4}$ In this study, EOL care selection, especially CAM use, influenced POD. Moreover, selection of best supportive care as EOL care associated with PCU as actual POD. Patients select aggressive anticancer therapies closer to death, with unintended consequences of late PCU referral. ${ }^{14}$ Moreover, physicians can predict the survival time of their patients based on experience and clinical data. ${ }^{15}$ On the other hand, patients pursue aggressive anticancer therapies, such as CAM use due to lack of awareness of their prognosis. Selecting a treatment mode without prediction of prognosis causes these patients to lose their chance of early reference to their preferred POD. 
Table 1 Patient characteristics

\begin{tabular}{|c|c|c|c|c|c|c|c|c|c|}
\hline \multirow[b]{2}{*}{ Total } & & \multirow[b]{2}{*}{$\begin{array}{l}\text { Total } \\
433\end{array}$} & \multicolumn{2}{|c|}{ PCU } & \multicolumn{2}{|c|}{$\begin{array}{l}\text { Home with } \\
\text { hospice }\end{array}$} & \multicolumn{2}{|c|}{$\begin{array}{l}\text { Non-PCU } \\
\text { Hospital }\end{array}$} & \multirow[b]{2}{*}{ p Value* } \\
\hline & & & $\begin{array}{l}n \\
147\end{array}$ & $\begin{array}{l}\text { Per cent } \\
34\end{array}$ & $\begin{array}{l}\mathrm{n} \\
57\end{array}$ & $\begin{array}{l}\text { Per cent } \\
13\end{array}$ & $\begin{array}{l}\mathrm{n} \\
229\end{array}$ & $\begin{array}{l}\text { Per cent } \\
53\end{array}$ & \\
\hline \multicolumn{10}{|l|}{ Age } \\
\hline Mean (SD) & & $64.8(9.3)$ & \multicolumn{2}{|c|}{$65.0(9.4)$} & \multicolumn{2}{|c|}{$66.5(8.8)$} & \multicolumn{2}{|c|}{$64.2(9.4)$} & \\
\hline$\geq 65$ & & 234 & 82 & 56 & 31 & 54 & 121 & 53 & 0.85 \\
\hline$<65$ & & 199 & 65 & 44 & 26 & 46 & 108 & 47 & \\
\hline \multicolumn{10}{|l|}{ Gender } \\
\hline Male & & 258 & 72 & 49 & 36 & 63 & 150 & 66 & 0.005 \\
\hline Female & & 175 & 75 & 51 & 21 & 37 & 79 & 34 & \\
\hline \multicolumn{10}{|l|}{ Close relative (caregiver) } \\
\hline \multirow[t]{2}{*}{ Spouse } & + & 334 & 110 & 75 & 44 & 77 & 180 & 79 & 0.70 \\
\hline & - & 99 & 37 & 25 & 13 & 23 & 49 & 21 & \\
\hline \multirow[t]{2}{*}{ Daughter(s) or son(s) } & + & 326 & 109 & 74 & 43 & 75 & 174 & 76 & 0.92 \\
\hline & - & 107 & 38 & 26 & 14 & 25 & 55 & 24 & \\
\hline \multirow[t]{2}{*}{ Parent(s) } & + & 13 & 5 & 3 & 1 & 2 & 7 & 3 & 0.82 \\
\hline & - & 420 & 142 & 97 & 56 & 98 & 222 & 97 & \\
\hline \multicolumn{10}{|l|}{ Distance from the cancer center } \\
\hline \multicolumn{2}{|l|}{ Mean (SD) (km) } & $32(78.1)$ & \multicolumn{2}{|c|}{$32(85.6)$} & \multicolumn{2}{|c|}{$16(10.4)$} & \multicolumn{2}{|c|}{$36.2(82.2)$} & \\
\hline $0-19$ & & 224 & 83 & 56 & 38 & 67 & 103 & 45 & 0.005 \\
\hline$\geq 20$ & & 209 & 64 & 44 & 19 & 33 & 126 & 55 & \\
\hline \multicolumn{10}{|l|}{ Attending physician } \\
\hline A & & 127 & 43 & 29 & 11 & 19 & 73 & 32 & 0.45 \\
\hline $\mathrm{B}$ & & 62 & 24 & 16 & 11 & 19 & 27 & 12 & \\
\hline $\mathrm{C}$ & & 114 & 35 & 24 & 16 & 28 & 63 & 28 & \\
\hline $\mathrm{D}$ & & 130 & 45 & 31 & 19 & 34 & 66 & 28 & \\
\hline \multicolumn{10}{|l|}{ State of disease } \\
\hline Advanced & & 350 & 114 & 78 & 47 & 82 & 189 & 83 & 0.46 \\
\hline Recurrence & & 83 & 33 & 22 & 10 & 18 & 40 & 17 & \\
\hline \multicolumn{10}{|l|}{ End-of-life care selection } \\
\hline Best supportive care & + & 357 & 129 & 88 & 48 & 84 & 180 & 79 & 0.07 \\
\hline & - & 76 & 18 & 12 & 9 & 16 & 49 & 21 & \\
\hline Non-standard chemotherapies & + & 64 & 14 & 10 & 8 & 14 & 42 & 18 & 0.06 \\
\hline & - & 369 & 133 & 90 & 49 & 86 & 187 & 82 & \\
\hline CAM & + & 57 & 10 & 7 & 7 & 12 & 40 & 17 & 0.01 \\
\hline & - & 376 & 137 & 93 & 50 & 88 & 189 & 83 & \\
\hline Medical environment & & & & & & & & & \\
\hline Involvement of a palliative care team & + & 44 & 13 & 9 & 5 & 9 & 26 & 11 & 0.69 \\
\hline & - & 389 & 134 & 91 & 52 & 91 & 203 & 89 & \\
\hline Involvement of a caseworker & + & 354 & 127 & 86 & 53 & 92 & 174 & 76 & 0.002 \\
\hline & - & 79 & 20 & 14 & 4 & 8 & 55 & 24 & \\
\hline Primary care doctor & + & 133 & 46 & 31 & 12 & 21 & 75 & 33 & 0.23 \\
\hline & - & 300 & 101 & 69 & 45 & 79 & 154 & 67 & \\
\hline
\end{tabular}

*Using $\chi^{2}$ test for categorical variables.

CAM, complementary and alternative medicine; PCU, palliative care units.

Geographical differences in established PCUs, BSC at home and regional hospitals with palliative care teams reduce the choice of POD available to patients. According to studies conducted in Europe, patients living in rural areas have increased difficulty in accessing healthcare $^{12}$ and palliative care $^{16}$; yet, they are more likely to die at home. ${ }^{4}$ In the present study, the choice of dying at home with hospice increased with the closer distance from the cancer centre, which is located in the centre of Tokyo. These results support the view that geographical trends affect the choice of POD in Japan and Europe.
The present study also showed that social support and involvement of a case worker affect the selection of POD. Specifically, social support influenced death at home through arrangement of medical environment by case workers. On the other hand, involvement of a palliative care team can potentially improve the timing of referral to a PCU. ${ }^{17}$ In this study, the palliative care team had no role in influencing the selection of POD of patients with cancer. Comprehensive cancer teams including the palliative care team, psycho-oncologist and case workers can involve patients in discussions about advance planning for care or POD. 
Table 2 Factors associated with place of death: multivariate analysis

\begin{tabular}{|c|c|c|c|c|}
\hline Place of death & Factors & $\mathbf{n}$ & OR $(95 \% \mathrm{Cl})$ & p Value * \\
\hline \multirow[t]{12}{*}{ PCU } & Gender & & & \\
\hline & Male & 72 & 1 (Ref) & 0.003 \\
\hline & Female & 76 & $1.85(1.23$ to 2.79$)$ & \\
\hline & Best suppo & & & \\
\hline & - & 18 & 1 (Ref) & 0.13 \\
\hline & + & 129 & $3.85(0.66$ to 25$)$ & \\
\hline & Non-standa & pies & & \\
\hline & - & 14 & 1 (Ref) & 0.15 \\
\hline & + & 133 & $3.00(0.68$ to 13.3$)$ & \\
\hline & CAM & & & \\
\hline & - & 137 & 1 (Ref) & 0.02 \\
\hline & + & 10 & $0.23(0.06$ to 0.81$)$ & \\
\hline \multirow[t]{6}{*}{ Home with hospice } & Distance frc & centre & & \\
\hline & 0-19 km & 38 & 1 (Ref) & 0.01 \\
\hline & $\geq 20 \mathrm{~km}$ & 19 & $0.47(0.26$ to 0.85$)$ & \\
\hline & Involvemen & ker & & \\
\hline & - & 5 & 1 (Ref) & 0.02 \\
\hline & + & 52 & $3.50(1.22$ to 10.03$)$ & \\
\hline \multirow[t]{18}{*}{ Non-PCU Hospital } & Gender & & & \\
\hline & Male & 150 & 1 (Ref) & 0.02 \\
\hline & Female & 79 & $0.61(0.41$ to 0.91$)$ & \\
\hline & Distance fro & centre & & \\
\hline & $0-19 \mathrm{~km}$ & 103 & 1 (Ref) & 0.002 \\
\hline & $\geq 20 \mathrm{~km}$ & 126 & $1.85(1.24$ to 2.74$)$ & \\
\hline & Best suppo & & & \\
\hline & - & 180 & 1 (Ref) & 0.45 \\
\hline & + & 49 & $0.53(0.10$ to 2.80$)$ & \\
\hline & Non-standa & pies & & \\
\hline & - & 42 & 1 (Ref) & 0.37 \\
\hline & + & 187 & $1.87(0.47$ to 7.35$)$ & \\
\hline & CAM & & & \\
\hline & - & 40 & 1 (Ref) & 0.13 \\
\hline & + & 189 & $2.41(0.76$ to 7.63$)$ & \\
\hline & Involvemen & ker & & \\
\hline & - & 55 & 1 (Ref) & 0.001 \\
\hline & + & 174 & 2.44 (1.43 to 4.17$)$ & \\
\hline
\end{tabular}

The trend of use of aggressive chemotherapy increased even in older patients, and the use of PCU as simply a place to die in rather than to control symptoms became common. ${ }^{9} 15$ In this study, $18 \%$ of patients with pancreatic cancer used aggressive anticancer treatment as EOL care. In the USA, the proportion of patients who choose cancer therapy at the EOL has increased from $13.8 \%$ to $18.5 \%{ }^{18}$ Our study shows a similar proportion when compared with previous reports. On the other hand, in this study, the prevalence of CAM use in patients with pancreatic cancer was $13 \%$. This rate was slightly lower than that found in previous studies. ${ }^{19} 20$ The prevalence of CAM use was potentially affected by several factors, including primary cancer site. In terms of cancer site, the rate of CAM use was higher in patients with lung, breast and hepatobiliary cancers than in those with other cancers, including gastrointestinal cancer. Hence, the ratio of CAM use in pancreatic cancer may be lower than that in the previous report. ${ }^{19}$ The multivariate analysis also revealed a close association between aggressive anticancer therapies and younger age. Previous studies showed that some factors, including younger age, were significant independent predictors of aggressive EOL care. ${ }^{9} 101921$

Certain limitations of this study should be considered, including its retrospective nature and the involvement of a single institution. Therefore, the findings may not be entirely representative of patients receiving cancer treatment at other Japanese cancer hospitals; moreover, we could not determine some other factors that influenced the selection of POD by patients with cancer. Above all, the study focused on factors associated with choosing EOL care and how these factors affect POD choice, but it did not include analysis of some other factors such as 
Table 3 Factors associated with end-of-life care selection: multivariate regression

\begin{tabular}{|c|c|c|c|c|}
\hline \multirow[b]{2}{*}{ End-of-life care } & \multirow[b]{2}{*}{ Factors } & \multirow[b]{2}{*}{$\mathbf{n}$} & \multicolumn{2}{|c|}{ Multivariate analyses } \\
\hline & & & OR (95\% Cl) & p Value ${ }^{*}$ \\
\hline \multirow[t]{6}{*}{ Best supportive care } & Age & & & \\
\hline & $\geq 65$ & 201 & 1 (Ref) & 0.04 \\
\hline & $<65$ & 156 & $0.60(0.36$ to 0.98$)$ & \\
\hline & State of disea & & & \\
\hline & Advanced & 295 & 1 (Ref) & 0.04 \\
\hline & Recurrence & 62 & $1.82(1.02$ to 3.23$)$ & \\
\hline \multirow[t]{3}{*}{ Non-standard chemotherapies } & Age & & & \\
\hline & $\geq 65$ & 25 & 1 (Ref) & 0.01 \\
\hline & $<65$ & 39 & 2.04 (1.18 to 3.51$)$ & \\
\hline \multirow[t]{8}{*}{ CAM } & Age & & & \\
\hline & $\geq 65$ & 20 & 1 (Ref) & 0.002 \\
\hline & $<65$ & 37 & $2.57(1.43$ to 4.63$)$ & \\
\hline & Attending phy & & & \\
\hline & A & 24 & 1 (Ref) & 0.03 \\
\hline & $B$ & 9 & 0.27 (0.11 to 0.62$)$ & 0.002 \\
\hline & C & 16 & 0.37 (0.13 to 1.02$)$ & $>0.05$ \\
\hline & $\mathrm{D}$ & 8 & 0.38 (0.15 to 0.94$)$ & 0.04 \\
\hline
\end{tabular}

income of patients, religion and timing of EOL discussions.

Physicians commonly avoid EOL care-related discussions with patients until they fail standard chemotherapy or are nearing death. ${ }^{22}$ Physicians who have close, long-term relationships with patients often wish to avoid discussions around EOL care. ${ }^{23}$ Physicians involved in longitudinal care, however, may be best equipped to have meaningful discussions about the patient's values and goals. ${ }^{5} \mathrm{NCCH}$, all attending physicians informed their patients before starting chemotherapy that advanced pancreatic carcinoma had reduced chances of being cured and that chemotherapy was of limited use in palliation and prolongation of survival. Some patients who discussed EOL care or POD during treatment with standard chemotherapy collaterally underwent a checkup or received palliative care in community hospitals or PCUs. The selection of CAM use as EOL care by the attending physician points to the critical need to recognise the lack of discussion with patients about EOL care. Moreover, selecting EOL care after failing standard chemotherapy had a direct bearing on the selection of POD.

In conclusion, the present study provides new and important information on the factors influencing patients' choices at the EOL. To the best of our knowledge, this is the first report of an investigation on POD that focuses on EOL care selection, especially aggressive anticancer treatment including CAM, among Japanese patients with pancreatic cancer. Importantly, patients and physicians should share the same information related to survival benefits and places to receive EOL care and choose appropriate POD.
Author affiliations

${ }^{1}$ Department of Experimental Therapeutics, Exploratory Oncology Research \& Clinical Trial Center, National Cancer Center, Tokyo, Japan

${ }^{2}$ Hepatobiliary and Pancreatic Oncology Division, National Cancer Center Hospital, Tokyo, Japan

${ }^{3}$ Epidemiology and Prevention Division, Research Center for Cancer Prevention and Screening, National Cancer Center, Tokyo, Japan

Acknowledgements The authors appreciate the contributions of Keiko Kondo and Rubi Mukoyama in collecting clinical data.

Contributors SK, HH and TS designed and participated in all stages of the study. SK, TS and HH participated in statistical analyses and discussion of the results. SK and HH recruited the patients. ST, TS, HH, CM, TO and HU helped to draft the manuscript. All authors read and approved the final manuscript.

Funding This work was supported in part by the National Cancer Center Research and Development Fund (23-A-14).

Competing interests None.

Ethics approval This study protocol was approved by the Institutional Review Board of the NCCH, Tokyo.

Provenance and peer review Not commissioned; externally peer reviewed. Data sharing statement No additional data are available.

Open Access This is an Open Access article distributed in accordance with the Creative Commons Attribution Non Commercial (CC BY-NC 3.0) license, which permits others to distribute, remix, adapt, build upon this work noncommercially, and license their derivative works on different terms, provided the original work is properly cited and the use is non-commercial. See: http:// creativecommons.org/licenses/by-nc/3.0/

\section{REFERENCES}

1. Morita T, Miyashita M, Shibagaki M, et al. Knowledge and beliefs about end-of-life care and the effects of specialized palliative care: a population-based survey in Japan. J Pain Symptom Manage 2006;31:306-16.

2. Steinhauser KE, Christakis NA, Clipp EC, et al. Factors considered important at the end of life by patients, family, physicians, and other care providers. JAMA 2000;284:2476-82. 
3. Miyashita M, Sanjo M, Morita T, et al. Good death in cancer care: a nationwide quantitative study. Ann Oncol 2007;18:1090-7.

4. Gomes B, Higginson IJ. Factors influencing death at home in terminally ill patients with cancer: systematic review. $B M J$ 2006;332:515-21.

5. Mack JW, Cronin A, Taback N, et al. End-of-life care discussions among patients with advanced cancer: a cohort study. Ann Intern Med 2012;156:204-10.

6. Weeks JC, Cook EF, O'Day SJ, et al. Relationship between cancer patients' predictions of prognosis and their treatment preferences. JAMA 1998;279:1709-14.

7. Smith TJ, Temin S, Alesi ER, et al. American Society of Clinical Oncology provisional clinical ppinion: the integration of palliative care into standard oncology care. J Clin Oncol 2012;30:880-7.

8. Wright AA, Zhang B, Ray A, et al. Associations between end-of-life discussions, patient mental health, medical care near death, and caregiver bereavement adjustment. JAMA 2008;300:1665-73.

9. Earle CC, Landrum MB, Souza JM, et al. Aggressiveness of cancer care near the end of life: is it a quality-of-care issue? J Clin Oncol 2008;26:3860-6.

10. Ho TH, Barbera L, Saskin R, et al. Trends in the aggressiveness of end-of-life cancer care in the universal health care system of Ontario, Canada. J Clin Oncol 2011;29:1587-91.

11. Yun YH, Lee MK, Park SM, et al. Effect of complementary and alternative medicine on the survival and health-related quality of life among terminally ill cancer patients: a prospective cohort study. Ann Oncol 2013;24:489-94.

12. Hunt R, McCaul K. A population-based study of the coverage of cancer patients by hospice services. Palliat Med 1996;10:5-12.

13. Koffman J, Higginson IJ. Dying to be home? Preferred location of death of first-generation black Caribbean and native-born white patients in the United Kingdom. J Palliat Med 2004;7:628-36.
14. Matsuyama R, Reddy S, Smith TJ. Why do patients choose chemotherapy near the end of life? A review of the perspective of those facing death from cancer. J Clin Oncol 2006;24:3490-6.

15. Glare $\mathrm{P}$, Virik $\mathrm{K}$, Jones $\mathrm{M}$, et al. A systematic review of physicians' survival predictions in terminally ill cancer patients. BMJ 2003;327:195-8.

16. Auchincloss AH, Van Nostrand JF, Ronsaville D. Access to health care for older persons in the United States: personal, structural, and neighborhood characteristics. J Aging Health 2001;13:329-54.

17. Morita $T$, Miyashita $M$, Tsuneto $S$, et al. Late referrals to palliative care units in Japan: nationwide follow-up survey and effects of palliative care team involvement after the Cancer Control Act. J Pain Symptom Manage 2009;38:191-6.

18. Grunfeld E, Lethbridge L, Dewar R, et al. Towards using administrative databases to measure population-based indicators of quality of end-of-life care: testing the methodology. Palliat Med 2006;20:769-77.

19. Hyodo I, Amano N, Eguchi K, et al. Nationwide survey on complementary and alternative medicine in cancer patients in Japan. J Clin Oncol 2005;23:2645-54.

20. Cassileth BR, Vickers AJ. High prevalence of complementary and alternative medicine use among cancer patients: implications for research and clinical care. J Clin Oncol 2005;23:2590-2.

21. Earle CC, Neville BA, Landrum MB, et al. Trends in the aggressiveness of cancer care near the end of life. J Clin Oncol 2004;22:315-21.

22. The AM, Hak T, Koëter G, et al. Collusion in doctor-patient communication about imminent death: an ethnographic study. $B M J$ 2000;321:1376-81.

23. Christakis NA, Lamont EB. Extent and determinants of error in doctors' prognoses in terminally ill patients: prospective cohort study. BMJ 2000;320:469-72. 